\title{
Checking Procedure of the Trieste (Italy) Subsea Pipeline by Transient Tests. Preliminary Results ${ }^{\dagger}$
}

\author{
Silvia Meniconi 1 ${ }^{1, *}$, Andrea Rubin ${ }^{2}$, Lorenzo Tirello ${ }^{2}$, Caterina Capponi ${ }^{1}$, Marco Cifrodelli ${ }^{1}$, \\ Pasquale Lucato ${ }^{2}$ and Bruno Brunone ${ }^{1}$ \\ 1 Department of Civil and Environmental Engineering, the University of Perugia, 06125 Perugia, Italy; \\ caterina.capponi@unipg.it (C.C.); marco.cifrodelli@ingpec.eu (M.C.); bruno.brunone@unipg.it (B.B.) \\ 2 AcegasApsAmga SpA (Hera Group), 35128 Padova, Italy; ARubin@acegasapsamga.it (A.R.); \\ LTirello@acegasapsamga.it (L.T.); pasqualelucato0@gmail.com (P.L.) \\ * Correspondence: silvia.meniconi@unipg.it; Tel.: +39-075-585-3893 \\ + Presented at the 4th International Electronic Conference on Water Sciences, 13-29 November 2019; \\ Available online: https://ecws-4.sciforum.net/.
}

Published: 12 November 2019

\begin{abstract}
The subsea transmission main (TM) of Trieste, Italy, plays a crucial role in the water supply system managed by AcegasApsAmga SpA (Hera Group). With the aim of implementing a systematic inspection procedure (at present divers are used for periodic surveys) AcegasApsAmga SpA decided to proceed with Transient Test-Based Techniques (TTBTs). In this paper, the results of preliminary transient tests generated by means of the existing devices (the first option to be considered within TTBTs) are discussed and possible alternatives are highlighted.
\end{abstract}

Keywords: subsea pipeline; fault detection; transient-test based techniques

\section{Introduction}

AcegasApsAmga SpA, of the Hera Group, manages the water systems of Padova and Trieste, in the northeastern part of Italy.

Within the water supply system of Trieste, with its very important port, the subsea transmission main (TM) plays a crucial role. In fact, it supplies not only the city but also the Carsico plateau. This iron DN1300 pipe has a length of about $19 \mathrm{~km}$ and conveys a discharge of about $750 \mathrm{~L} / \mathrm{s}$ with a steady-state pressure equal to 7-10 bars according to the elevation. Since at present the inspection of the Trieste TM is executed by divers, there is the need to implement a systematic, and possibly not too expensive, fault detection procedure.

In recent decades, several technologies have been proposed for fault (e.g., leak) detection in water distribution networks (WDNs). On the contrary, there are some limitations for TMs for which the present most common fault detection technologies are of in-line type with tethered and freeswimming sensors or acoustic correlators placed inside the pipelines (see, as an example, www.puretechltd.com). A further option is the continuous monitoring at measurement sections situated quite close to each other, that is, at a distance of a few hundred meters (see, for example, www.echologics.com). Because of the large length of the Trieste TM and its clear inaccessibility along the route, the use of the Transient Test-Based Techniques (TTBTs) has been explored.

When TTBTs are used, pressure waves are generated to explore the system. It is worth noting that TTBTs can be used to detect not only leaks but also other types of faults, such as partial blockages, partially closed in-line valves, pipe wall deterioration, and illegal branches. In fact, any of such anomalies give rise to a reflected pressure wave whose characteristics allows understanding its nature, and detecting its location and size [1-4]. 
Within TTBTs, the choice of the suitable procedure for generating pressure waves, that guarantees the diagnosis of the system without compromising its integrity, is one of the most important decision to take. According to the literature (e.g., [5-8]), the choice of the transient test procedure is strongly linked to the characteristics of the system and operating conditions. However, the first and most obvious option is to generate transients by means of the installed devices (e.g., by maneuvering (closing) valves and pumps, the so-called "explorative" tests). It is worth noting that even if such a preliminary phase may be quite time consuming, it is definitely essential. In fact, it allows understanding the transient response of the system and then designing the most appropriate type of test. Once it has been ascertained that such transients are not suitable (in other words, because of the characteristics of the generated pressure waves they do not allow detecting possible faults), alternative methods for pressure wave generation must be implemented.

In this paper the results of some "explorative" (preliminary) tests executed in the Trieste TM are reported and discussed in the view of the assessment of a reliable and safe fault-detection test procedure.

\section{Explorative Transient Tests}

The layout of the investigated system is reported in Figure 1. The Randaccio pumping station supplies the TM, which is protected against the water-hammer overpressures by means of the Petrinia piezometric tower. The small WDN of the "Villaggio del Pescatore" is supplied by the TM through a dedicated branch. At present, two valves are installed on land: the first (VP), at about the inlet section, and the second (VM), at about the downstream end section. Preliminarily, the option of maneuvering the VP valve was excluded since it is too close to reflecting boundaries (i.e., the Petrinia piezometric tower and the "Villaggio del Pescatore" WDN). As a consequence, possible "explorative" transients could be those caused by: (i) switching-off the pumps at the Randaccio pumping station, and (ii) totally closing the downstream end valve VM. The pressure time-history during transient tests (hereafter referred to as the pressure signal, $H$ ) was acquired by means of piezoresistive transducers (Figure 2a) with a frequency acquisition of $1000 \mathrm{~Hz}$ at two measurement sections: section P (Figure 2b), just downstream of the VP valve, and section M (Figure 2c), just upstream of the VM valve. It is worth noting that within TTBTs there is no need of measuring the discharge during the tests.

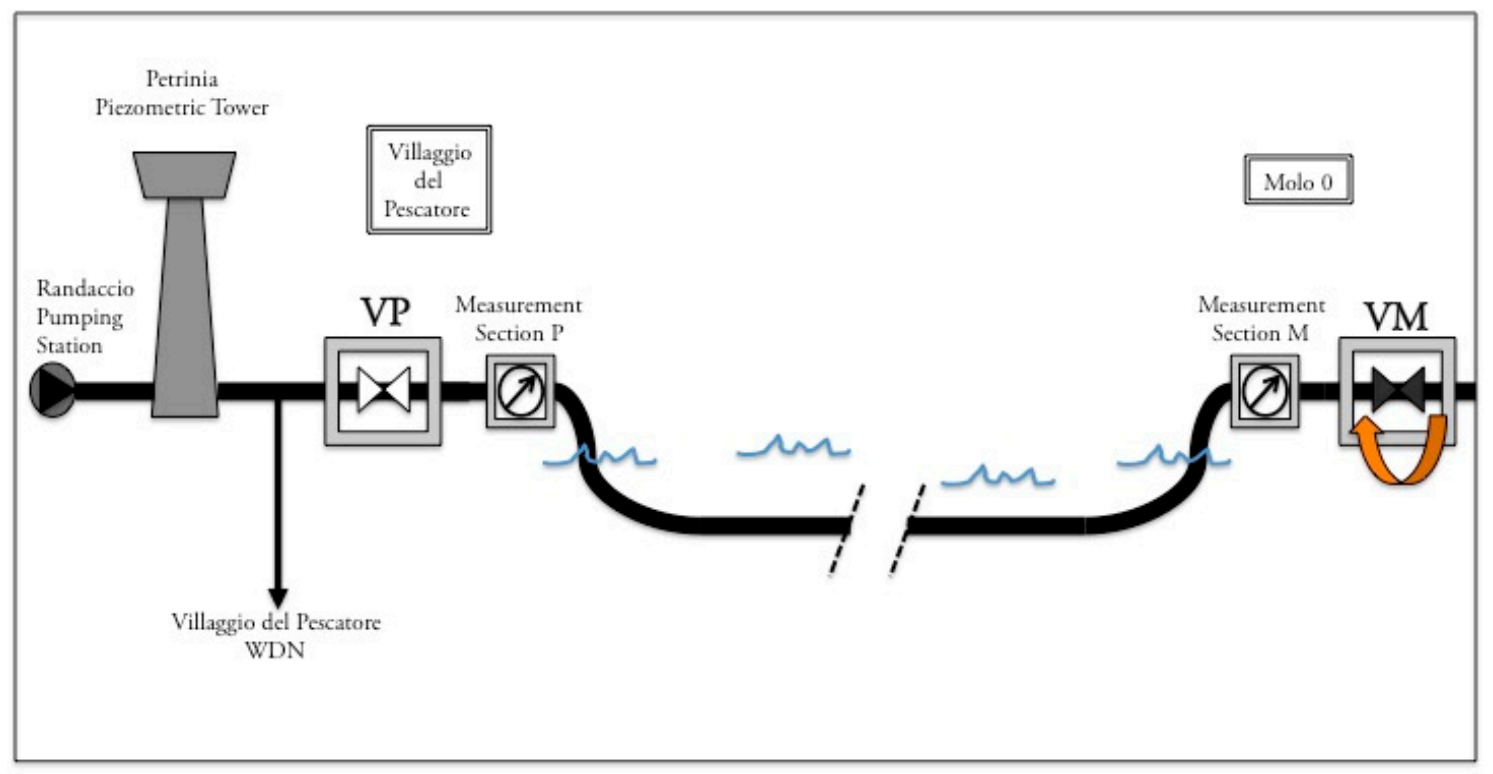

Figure 1. Schematic of the Trieste subsea transmission main (TM) managed by AcegasApsAmga SpA (Hera Group). 


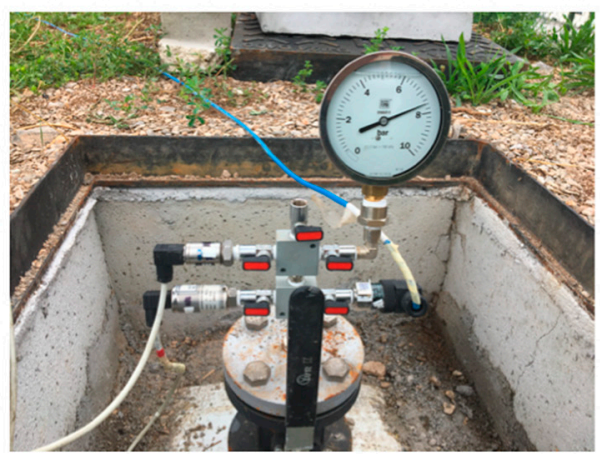

(a)

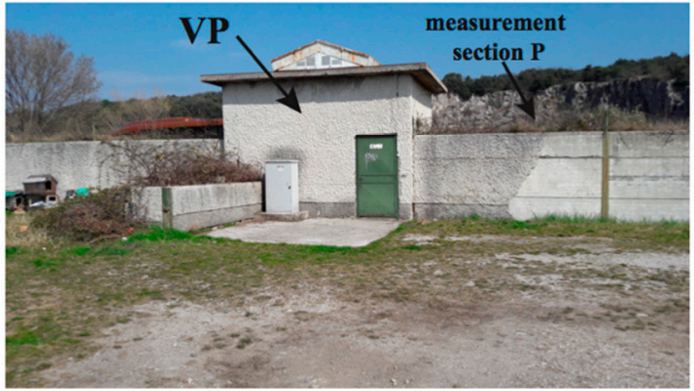

(b)

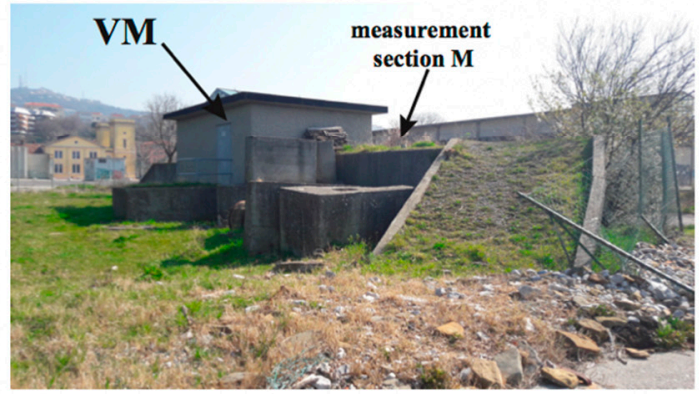

(c)

Figure 2. Trieste subsea TM: (a) pressure transducers installed at the measurement sections: (b) section $\mathrm{P}$, downstream of the VP valve; (c) section $\mathrm{M}$, upstream of the VM valve.

\subsection{Transient Generated by the Pump Switching-Off at the Randaccio Pumping Station}

At the Randaccio pumping station, the first pump switching-off caused a very slow pressure reduction that started at section $\mathrm{P}$ at $t=39 \mathrm{~min}, 34 \mathrm{~s}$ (Figure 3). According to the characteristics of the system and, very important, the place where such a transient was generated, the acquired pressure signals were not suitable for fault detection. Precisely, the following aspects must be taken into account: (i) the Petrinia piezometric tower is situated between the section where the pressure waves are injected into the system and the system itself (as a consequence, it behaves as a sort of filter with the inertia of the mass of the water in the tower playing a very important role); (ii) the pump switching-off is a slow maneuver because of the inertia of the pumps (as a consequence, the generated pressure waves are not sharp enough [9] for a reliable fault detection [10]); and (iii) the "Villaggio del Pescatore" WDN, even if with a limited size, inevitably corrupts the pressure signal (in other words, the pressure waves generated in such a WDN make very arduous the analysis of the pressure signals). For the objection that the abovementioned negative aspects were absolutely predictable, it can be replied that the pump switching-off is a very simple and routine test. Nonetheless, it contributes to the knowledge of the transient behavior of the system. 


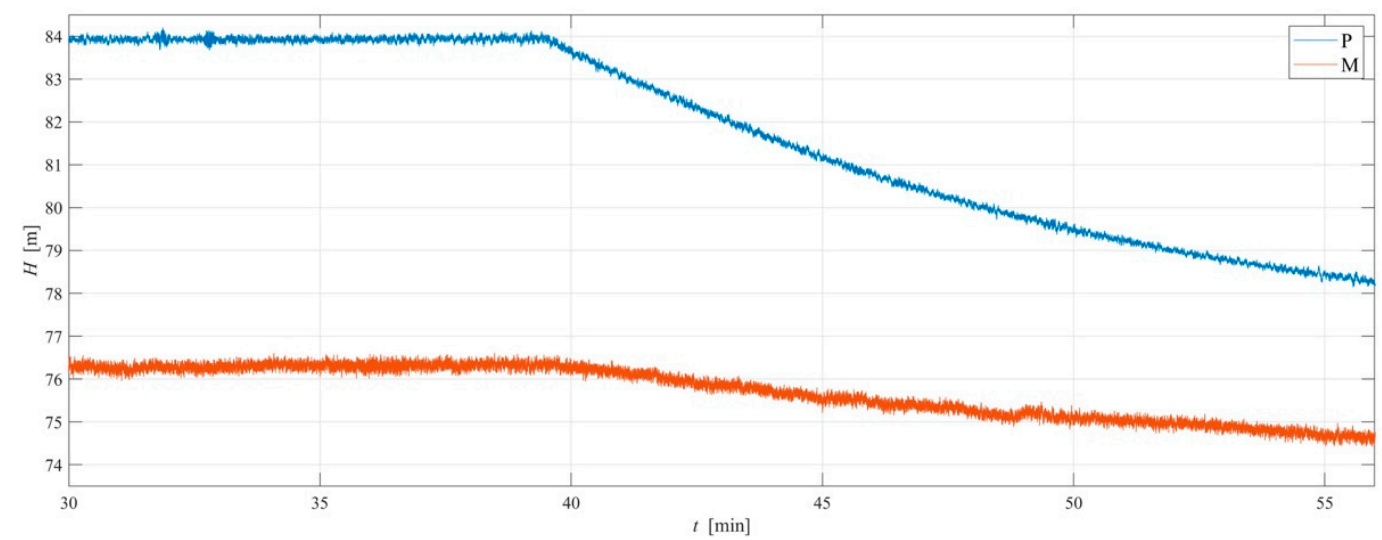

Figure 3. Trieste subsea TM: pressure signals acquired at the measurement sections during transients generated by switching-off the pumps at the Randaccio pumping station.

\subsection{Transient Generated by the Closure of the VM Valve}

Before totally closing the VM valve (Figure 4), the discharge in the TM was significantly reduced for the following reasons: (i) to generate a safe pressure variation (i.e., few meters of water column); and (ii) to make the closure as fast as possible in order to obtain sharp pressure waves [10]. With this aim, preliminarily the pumps at the Randaccio pumping station were switched-off (Figure 3) and then the VM valve was slowly and manually partially closed. After the pump switching-off, the flow direction reversed and the TM was supplied by the Trieste WDN downstream of "Molo 0". In fact, the manual partial closure of the VM valve caused a pressure decrease at $t=65 \mathrm{~min}, 11 \mathrm{~s}$. Moreover, within the executed "transient sequence" (first step: pump switching-off; second step: slow partial closure of the VM valve; third step: fast complete closure of the VM valve), according to the actual flow direction, the effects of the final maneuver (i.e., the fast closure of the VM valve) which happened at $t=82 \mathrm{~min}, 30 \mathrm{~s}$ were those of a maneuver executed at the initial section of the TM. As designed, the maximum value of the pressure oscillations was quite small and equal to about $2.7 \mathrm{~m}$ (see the upper box in Figure 5), and the used "transient sequence" was surely safe. However, notwithstanding the preliminary partial closure of the VM valve, the final closure was not fast enough since it was manual. Such a feature implies that reflected pressure waves cannot be detected in the pressure signals and the executed transient is not reliable for fault detection. However, in terms of the transient response of the system, useful information was obtained about: (i) the pressure decay after the completion of the maneuver, and (ii) the pressure wave speed, $a$. Precisely, notwithstanding the large values of both the length and diameter of the TM [11], a very slow decay of the pressure signal was observed. In fact, as clearly highlighted in Figure 5, the duration of the pressure oscillations due to the fast closure of the VM valve was larger than $48 \mathrm{~min}$. Based on the pressure wave arrival times at the measurement sections, the value $a=1159 \mathrm{~m} / \mathrm{s}$ was obtained. It is worth noting that the knowledge of the value of the pressure wave speed is of a crucial importance for designing safely any maneuver. 


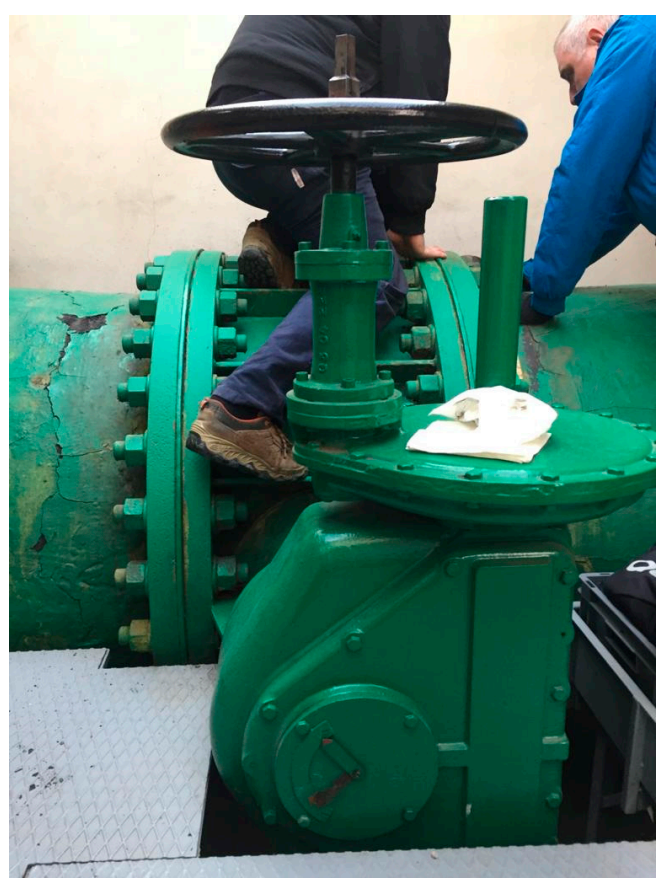

Figure 4. Trieste subsea TM: The VM valve at "Molo 0".

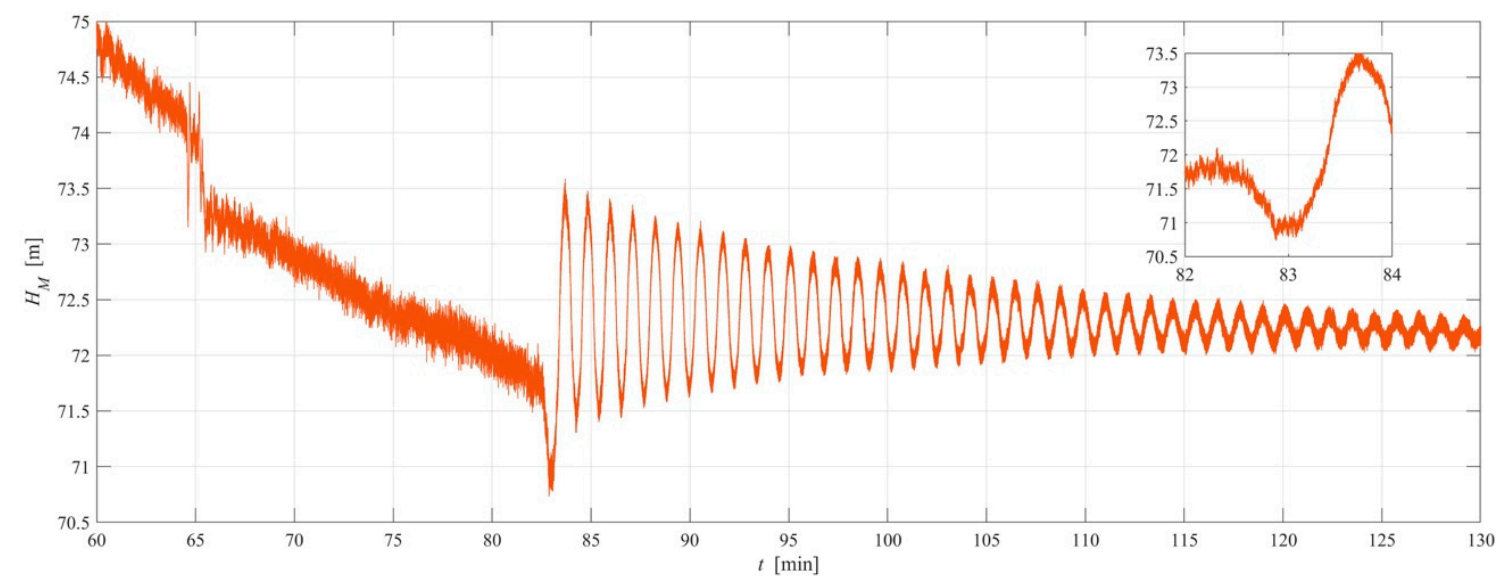

Figure 5. Trieste subsea TM: pressure signals acquired at the measurement sections during transients generated by the closure of the VM valve at "Molo 0". In the upper box, a magnification of the first characteristic period of the pressure signal after the total closure of the valve VM is reported.

\section{Conclusions}

At present, the inspection of the Trieste subsea TM is executed by divers. To reduce costs and increase the frequency of the inspections, AcegasApsAmga SpA (Hera Group), who manages the system, decided to implement a systematic fault detection procedure. Because of the large length of the TM and its inaccessibility along the route, the option constituted by the transient test-based techniques (TTBTs) has been explored. Within TTBTs, preliminary tests concerned the pump switching-off at the Randaccio pumping station and the closure of the valve installed at the downstream end section of the TM. Such tests, even if useless for fault detection, provided a better insight into the transient response of the system.

In the continuation of the analysis, the following alternative solutions for generating a reliable transient for fault detection will be examined: (i) maneuvering a small-diameter side discharge valve, and (ii) connecting the Portable Pressure Wave Maker (PPWM) device refined at the Water Engineering Laboratory (WEL) of the University of Perugia [5]. 
Author Contributions: S.M., A.R., L.T., C.C., M.C., P.L. and B.B. conceived, designed and performed the experiments; S.M., C.C., M.C. and B.B. analyzed the data and wrote the paper. All authors have read and agreed to the published version of the manuscript.

Acknowledgments: This research has been funded by AcegasApsAmga SpA (Hera Group) and the Hong Kong (HK) Research Grant Council Theme-Based Research Scheme and the HK University of Science and Technology (HKUST) under the project "Smart Urban Water Supply System (Smart UWSS)". Support from Italian Ministry of Education, Research and University (MIUR) and University of Perugia is acknowledged within the program "Dipartimenti di Eccellenza 2018-2022". The support of Claudio Del Principe for the field tests is highly appreciated.

Conflicts of Interest: The authors declare no conflict of interest.

\section{References}

1. Colombo, A.F.; Lee, P.; Karney, B.W. A selective literature review of transient-based leak detection methods. J. Hydro-Environ. Res. 2009, 2, 212-227.

2. Xu, X.; Karney, B. An overview of transient fault detection techniques. In Modeling and Monitoring of Pipelines and Networks; Verde, C., Torres, L., Eds.; Springer: Cham, Switzerland, 2017; pp. 13-37.

3. Ayati, A.H.; Haghighi, A.; Lee, P.J. Statistical review of major standpoints in hydraulic transient-based leak detection. J. Hydraul. Struct. 2019, 5, 1-26.

4. Liu, Z.; Kleiner, Y. State of the art review of inspection technologies for condition assessment of water pipes. Measurement 2013, 46, 1-15.

5. Brunone, B.; Ferrante, M.; Meniconi, S. Portable pressure wave-maker for leak detection and pipe system characterization. J. AWWA 2008, 100, 108-116.

6. Gong, J.; Lambert, M.F.; Nguyen, S.T.N.; Zecchin, A.; Simpson, A.R. Detecting thinner-walled pipe sections using a spark transient pressure wave generator. J. Hydraul. Eng. 2018, 144, 06017027.

7. Taghvaei, M.; Beck, S.B.M.; Boxall, J. Leak detection in pipes using induced water hammer pulses. Int. J. Comadem 2010, 13, 19-25.

8. Stephens, M.; Lambert, M.F.; Simpson, A.S. Determining the internal wall condition of a water pipeline in the field using an inverse transient, J. Hydraul. Eng. 2013, 139, 310-324.

9. Meniconi, S.; Brunone, B.; Ferrante, M.; Capponi, C.; Carrettini, C.A.; Chiesa, C.; Segalini, D.; Lanfranchi, E.A. Anomaly pre-localization in distribution-transmission mains by pump trip: Preliminary field tests in the Milan pipe system. J. Hydroinform 2015, 17, 377-389.

10. Meniconi, S.; Brunone, B.; Ferrante, M.; Massari, C. Small amplitude sharp pressure waves to diagnose pipe systems. Water Resour. Manag. 2010, 25, 79-96.

11. Duan, H.F.; Ghidaoui, M.S.; Lee, P.J.; Tung, Y.K. Relevance of unsteady friction to pipe size and length in pipe fluid transients. J. Hydraul. Eng. 2012, 138, 154-166.

(C) 2019 by the authors. Licensee MDPI, Basel, Switzerland. This article is an open access article distributed under the terms and conditions of the Creative Commons Attribution (CC BY) license (http://creativecommons.org/licenses/by/4.0/). 